\title{
Endogenous Third-Degree Price Discrimination in a Supply Chain with One Common Manufacturer and Duopoly Retailers
}

\author{
Hongmei Yang ${ }^{1}$ and Wei Wang $\mathbb{D}^{1,2}$ \\ ${ }^{1}$ School of Economics, Ocean University of China, Qingdao 266100, China \\ ${ }^{2}$ Marine Development Studies Institute of OUC, Key Research Institute of Humanities and Social Sciences at Universities, \\ Ministry of Education, Qingdao 266100, China \\ Correspondence should be addressed to Wei Wang; walker@ouc.edu.cn
}

Received 9 October 2020; Revised 19 November 2020; Accepted 10 December 2020; Published 23 December 2020

Academic Editor: Luca Pancioni

Copyright (c) 2020 Hongmei Yang and Wei Wang. This is an open access article distributed under the Creative Commons Attribution License, which permits unrestricted use, distribution, and reproduction in any medium, provided the original work is properly cited.

\begin{abstract}
Assuming the two retailers decide whether to acquire information to segment consumers and price them differently, we investigate the problem of information acquisition and third-degree price discrimination in the supply chain composed of one common manufacturer and duopoly retailers. We explore how the supply chain members' pricing decisions are affected by the fraction of high price-sensitivity consumers and the consumers' difference in price sensitivity. Analytical results show that the manufacturer's wholesale price increases with the fraction of high price-sensitivity consumers and decreases with the consumers' difference in price sensitivity. Moreover, if a retailer chooses to acquire information and price discriminate, the retail prices for two types of consumers increase with the fraction of high price-sensitivity consumers. However, the retail price for consumers with high (low) price sensitivity decreases (increases) with the consumers' difference in terms of price sensitivity. By comparing the results among different information acquisition and price discrimination decisions, we find that there exist two possible equilibrium decisions for both retailers: both retailers acquire information and price discriminate and no retailer acquires information and each charges a uniform price for all consumers. The strategy which dominates depends on the fraction of high price-sensitivity consumers and the consumers' difference in price sensitivity. However, compared with no retailer acquiring information, the manufacturer is better off when two retailers acquire information. Consequently, the manufacturer designs a fixed fee contract to stimulate retailers to price discriminate and to achieve a win-win situation for them finally.
\end{abstract}

\section{Introduction}

With the progress of information technology and data science, retailers have more incentives to collect consumers' purchase history data. For example, retailers can track customers' purchase histories by using optical scanning, Internet cookies, loyalty cards, and other automatic data collection devices. Coupled with the recent emergence of cloud computing and big data technologies, retailers' ability to price discriminate based on purchase history of consumers has been enhanced greatly. By acquiring and analyzing consumers' purchase information, retailers can classify new and existing customers and charge them different prices. Therefore, price discrimination has become a prevalent business strategy. For example, the new customers can obtain the free delivery service from the online retailer AuchanDirect, and the existing consumers can obtain a discount for the season ticket renewed by Parisian rugby club Stade Francais CASG [1].

This increasing practice also has attracted a lot of attention among scholars in the last few years. The scholars referred to this phenomenon as behavior-based price discrimination (BPD) in the literature and attempted to give some useful insights about its profitability. For example, Jeong and Maruyama [2] use a two-period model to study whether firms need to adopt BPD in markets with switching costs. They find that both firms selecting uniform pricing is the dominant strategy. Choe et al. [3] study how the BPD affects firms' prices and profits over the two periods. They show that, compared with the strategy that both firms adopt 
uniform pricing, BPD makes the two firms gain less profits. Esteves and Reggiani [4] study the effect of the demand elasticity on the BPD. They find that, compared with the scenario where firms charge a uniform price for consumers, the firms are worse off when they adopt BPD. Moreover, they show that the negative impact of $\mathrm{BPD}$ decreases with the increases of demand elasticity. Estevers [5] explore the relationship between BPD and retention offers, assuming that the firms give their customers a retention discount to reduce switching. He finds that the BPD is also detrimental to both firms. In general, these studies all show that adopting $\mathrm{BPD}$ strategy is bad for firms. Other researchers have shown that BPD strategy can be profitable under some conditions. For example, Shin and Sudhir [6] find that firms can adopt BPD when customers' demands are heterogeneous. Jing [7] finds that BPD can be profitable when customers are uncertain about an experience. Pazgal and Soberman [8] find that a firm can benefit from BPD if it gives returning customers additional benefits. Li and Jain [9] find that adopting $\mathrm{BPD}$ is more profitable than setting a uniform price for all consumers if consumers' fairness concerns are sufficiently strong. Following them, Jing [10], Rhee and Thomadsen [11], Li [12], and Zhou et al. [13] also study the conditions where BPD can be profitable.

The above literature studying BPD all assumed that the information obtained by firms only helps firms to distinguish consumers between their own and rivals (called the first piece of information) and price them differently. Very limited studies focus on additional information about consumers from their purchasing histories. However, in the era of big data, with the improvement of data analysis technologies, in addition to the first type of information, the consumers' characteristics information (called the second piece of information) is also available to the firms. For example, the firms can mine the consumers' characteristics (e.g., preference, sensitivity, and fairness) by using user profile technology to analyze consumers' information obtained by firms.

The consumers' price sensitivity is a valuable and common second piece of information for firms [14-17]. With "price sensitivity," we mean that extent to which a variation of the price of the good affects the utility of a consumer buying that good (see, for example, Erdem et al. [18]). In this respect, a firm can learn about the consumers' price sensitivity from their purchasing information and properly design-targeted prices for different price-sensitivity consumers. Therefore, in our paper, we assume that the two retailers are able to obtain the two pieces of consumers' information and set different prices for different-type consumers.

The study that is the closest to ours is Colombo [19]. He assumes that each firm is able to distinguish between the consumers who have bought from it and those who bought from the rival. Furthermore, each firm can learn about the price sensitivity of their own consumers. Building a twoperiod model (in the first period, firms have no information to segment consumers. After observing consumers' purchasing behavior, firms divide consumers into new and returning customers, as well as the high price-sensitivity and low price-sensitivity consumers in the second period, and price accordingly.) of behavior-and characteristic-based price discrimination, he studies whether firms can benefit from price discrimination. He also discusses the implications of price discrimination on consumer surplus and welfare.

This paper differs from Colombo [19] in two aspects. On the one hand, Colombo [19] assumes that the price discrimination is an exogenous setting. Once consumers make their purchasing decisions in the first period, the consumers' purchasing information is available to the firms in the second period. Then, firms use the information to segment consumers into different groups and price them differently. In contrast, we endogenize retailers' decisions to acquire information and price discriminate and make them be the retailers' decision variables. Under this setting, the two retailers can endogenously decide to acquire information and price discriminate or not. If a retailer finds that price discriminate between different types of customers is bad, it can choose not to obtain the information and sets a uniform price for all consumers. We try to explore which option of information acquisition and price discrimination is optimal for two retailers.

On the other hand, Colombo [19] examines price discrimination in a nonchannel setting. He mainly focuses on horizontal competition between two firms and explores how the price discrimination affects two firms' performance, consumer surplus, and social welfare. On the contrary, in our paper, we study information acquisition and price discrimination in a channel setting in which a common manufacturer sells to consumers through two retailers. Our main contribution is introducing channel's vertical competition between channel members and showing how the retailers' different options of information acquisition and price discrimination impact the manufacturer's and retailers' performance, as well as the whole channel's performance.

Motivated by the facts discussed above, we seek to answer the following questions. (i) What are the effects of the consumers' difference in price sensitivity and the fraction of high price-sensitivity consumers on the manufacturer's and the two retailers' pricing decisions? (ii) Should two competing retailers acquire information and price discriminate when they face competition in the supply chain? (iii) How do the two retailers' pricing discrimination strategies influence the manufacturer's and the whole supply chain's performance?

To answer these questions, we formulated an information acquisition and third-degree price discrimination game in the supply chain with one common manufacturer and two competing retailers. We assume that the two retailers could choose to acquire information and price discriminate or not. We also assume that if retailers choose to acquire information, they can distinguish not only between their own and rival's consumers but also the consumers' price sensitivity (high price sensitivity or low price sensitivity). Based on two retailers' choices of information acquisition and price discrimination, three possible information acquisition and price discrimination structures are built: (i) no retailer 
acquires information and each sets a uniform price; (ii) only one retailer acquires information and price discriminates; and (iii) both retailers acquire information and price discriminate. This paper yields a number of interesting results based on the analysis of the equilibrium solutions.

First, we show that the fraction of high price-sensitivity consumers and the consumers' difference in price sensitivity affect the supply chain members' pricing decisions. Specifically, the manufacturer's wholesale price increases with the increase of fraction of high pricesensitivity consumers while decreases with the difference in price sensitivity. Moreover, when the retailer chooses to acquire information and price discriminates, the selling prices set by the retailer for consumers with different price sensitivities increase with the fraction of high pricesensitivity consumers. However, the retailer's selling prices on consumers with high (low) price sensitivity decrease (increase) with the consumers' difference in terms of price sensitivity.

Second, we show whether the two retailers' choice to acquire information and price discriminate is affected by the two factors: the fraction of high price-sensitivity consumers and the consumers' difference in price sensitivity. Specifically, the two retailers will choose to acquire information and price discriminate only if the consumers' difference in price sensitivity is sufficiently large and there exist lots of consumers with high price sensitivity. Otherwise, the optimal strategy is that no retailer acquires information and each of them sets a uniform price as an optimal strategy.

Third, we find that the retailers' strategies of information acquisition and price discrimination also affect the manufacturer's performance, as well as the whole supply chain's performance. On the one hand, for the common manufacturer, the strategy of both retailers acquiring information and price discriminating always makes the manufacturer get the highest profit compared to the other two strategies. On the other hand, the strategy of both retailers acquiring information and price discriminating also makes the whole supply chain better off.

Finally, we find that, choosing a proper value of the fixed fee, a fixed fee contract designed by the manufacturer can be used to stimulate the two retailers to acquire consumer's information and practice price discrimination regardless of the difference of price sensitivity and the fraction of high price-sensitivity consumers.

The rest of this paper is organized as follows. In Section 2 , we present the models, the notations, and the assumptions of this paper. In Section 3, we formulate the equilibrium solutions of different models at the second stage and analyze the effects of two parameters on pricing decisions: the fraction of high price-sensitivity consumers and the consumers' difference in price sensitivity. We also compare and analyze the equilibrium profits among different models in Section 3. In Section 4, we analyze and compare the two retailers' equilibrium information acquisition decisions at stage 1. In Section 5, we design a fixed fee contract for the manufacturer to motivate the two retailers to choose to acquire information at the first stage. Finally, Section 6 concludes this paper. Appendix provides the proofs of all propositions and corollaries.

\section{The Model}

Consider a standard supply chain in which a manufacturer (it is denoted by $M$ ) sells his product through two competing retailers (she and he are denoted by $R_{1}$ and $R_{2}$ ). The two retailers are identical except for the choice of information acquisition and price discrimination. Moreover, both retailers compete in a linear market of one unit length. $R_{1}$ and $R_{2}$ occupy the endpoints of this linear market, namely, 0 and 1 , respectively. Figure 1 shows the supply chain structure.

Consumers are uniformly distributed along the linear market. We assume density is one, and we denote by $x \in[0,1]$ the location of each consumer in the market. Therefore, the $x$ indicates the preferred variety of a given product for a consumer located at $x$. The more distant the product is from $x$, the less utility the consumer gets from the product. Furthermore, we assume that, at any location $x$, there are two types of consumers: consumers with a high price sensitivity $(H)$ and consumers with a low price sensitivity $(L)$. Specifically, at each point of the linear market, there is a fraction $\lambda \in(0,1)$ of $H$-type consumers and a fraction $1-\lambda$ of $L$ - type consumers. Because the elasticity of demand to price is inversely related to income [20], $L$ can be interpreted as "rich" consumers, whereas $H$ can be interpreted as "poor" consumers.

Suppose that both retailers have access to acquire the information that allows the retailers to divide consumers into two equal groups: market $A$ with consumers located to the left of $1 / 2$ and market $B$ with consumers located to the right of the middle line (in this paper, we assume that the consumers in the market $A(B)$ have bought products from $R_{1}\left(R_{2}\right)$. As a result, if the retailers choose to acquire information, they can distinguish consumers between own and rivals and price discriminate to keep own consumers and poach rival's consumers.). Moreover, among consumers who belong to different markets, the retailers with information can distinguish between $L$-type consumers and $H$-type consumers. Note that although it is reasonable to assume that the retailer needs to pay a fixed cost $c$ for acquiring information, this $c$ is normalized to zero in our basic model to highlight the intriguing result that the retailer may commit to no acquiring information even though it is costless to do so.

Based on two retailers' choices of information acquisition and price discrimination, three possible information acquisition and price discrimination structures are built: Models NN (no retailer acquires information and each sets a uniform price), NI or IN (only one retailer acquires information and price discriminates), and II (both retailers acquire information and price discriminate). Here, the $I$ represents "acquire information and price discriminate" and $N$ represents "not acquire information and set a uniform price." 


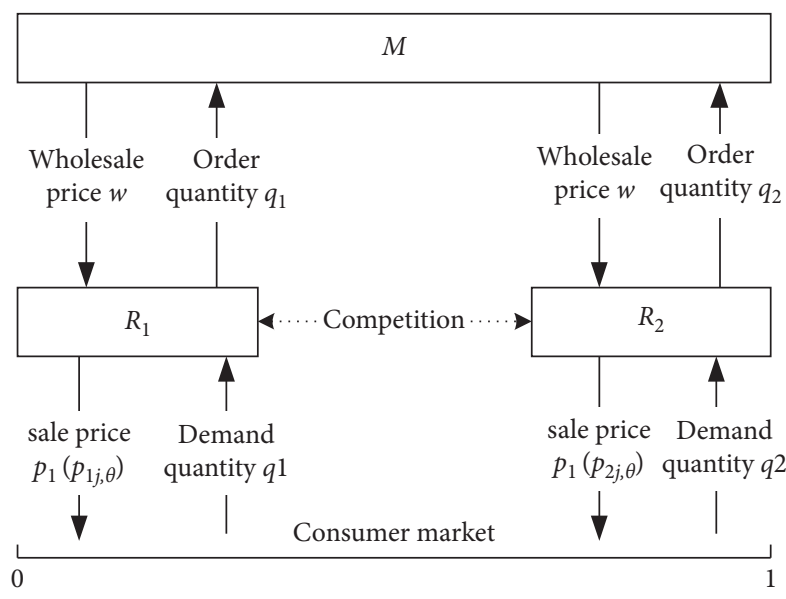

Figure 1: The supply chain structure.

We consider the following sequence of events:

(a) The manufacturer, as the supply chain's leader, sets the wholesale price $w$ for two retailers firstly.

(b) Given the manufacturer's wholesale price, the two retailers, as followers of the supply chain, simultaneously and independently determine their selling prices. Specifically, if a retailer chooses to acquire information and price discriminate, she/he sets different prices for different-type consumers in markets $A$ and $B$; otherwise, she/he charges a uniform price for different-type consumers in both market.

Now, we will introduce the consumers' preferences. Denote the retail price set by retailer $i=\{1,2\}$ with $p_{i}$ if she (he) does not acquire information and set a uniform price. Furthermore, we denote by $p_{i k, \theta}$ the price set by retailer $i$ on the $\theta$-type consumers in $k$ market, with $k=\{A, B\}$ and $\theta=\{L, H\}$. Consider a $\theta-$ type consumer located at $x$ who buys from retailer $i=\{1,2\}$. He sustains transportation cost equal to $t T^{i}$, with $T^{i}=\left\{\begin{array}{ll}x, & \text { if } i=1, \\ 1-x, & \text { if } i=2,\end{array}\right.$ and $t>0$. When the retailer chooses not to acquire information and set a uniform price, the utility of the consumer is $v-\alpha_{\theta} p_{i}-t T^{i}$. When the retailer decides to acquire information and price discriminate, the utility of the consumer is $v-\alpha_{\theta} p_{i k, \theta}-t T^{i}$, where $v$ is a consumer's utility derived from the product and $\alpha_{\theta}$ measures the price sensitivity of $\theta$ - type consumers.

Specifically, following Colombo [19] study, we assume that $\alpha_{L}=1-\lambda \beta$ and $\alpha_{H}=1+(1-\lambda) \beta$, in which $\beta$ measures the consumers' difference in terms of price sensitivity, $\alpha_{H}-\alpha_{L}$. The higher $\beta$ is, the lower (higher) the price sensitivity of $L(H)$-type consumers is. Moreover, the two types of price sensitivity are related to the distribution of types, $\lambda$. The price sensitivities of both-type consumers increase with the decrease of the fraction of $H$-type consumers, $\lambda$. This can be explained by real income. Indeed, for given nominal values of income of poor and rich consumers, when the number of "rich" consumers ( $L-$ type consumers) is greater (smaller), the real value of income of both poor and rich is smaller (greater), resulting in two types of price sensitivities which are greater (smaller). We summarize notations, which will be used in this paper, in Table 1.

In this paper, we only analyze the situation in which the following conditions hold:

(i) $\alpha_{\theta}\left(p_{1}+p_{2}\right) \leq 2 v-t_{1}$, for NN model

(ii) $\alpha_{\theta}\left(p_{1 k, \theta}+p_{2}\right) \leq 2 v-t_{2}$, for IN model

(iii) $\alpha_{\theta}\left(p_{1 k, \theta}+p_{2 k, \theta}\right) \leq 2 v-t_{3}$, for II model

These conditions guarantee the market is fully covered.

\section{Equilibrium Analysis among Different Models}

In this section, we derive the equilibrium solutions of three models: (i) no retailer acquires information and each sets a uniform price (NN); (2) only one retailer acquires information and price discriminates (IN); and (iii) both retailers acquire information and price discriminate (II). In addition, we investigate the impacts of the fraction of $H$-type consumers $(\lambda)$ and the consumers' difference in price sensitivity $(\beta)$ on optimal pricing decisions in the supply chain. Finally, we compare and explore the effects of retailers' decisions of information acquisition and price discrimination on the performance of supply chain members.

3.1. NN Model. Now, consider the scenario where no retailer chooses to acquire information to segment consumers and each retailer sets a uniform price for all consumers. Consider a generic indifferent $\theta$-type consumer, with $\theta=\{L, H\}$, which can be obtained by $\alpha_{\theta} p_{1}+t x_{\theta}=\alpha_{\theta} p_{2}+t\left(1-x_{\theta}\right)$. Therefore, the location of $\theta-$ type indifferent consumer in the market is

$$
x_{\theta}=\frac{\left(p_{2}-p_{1}\right) \alpha_{\theta}}{2 t}+\frac{1}{2} \text {. }
$$

Figure 2 illustrates the market sharing between the two retailers. In Figure 2, above (below) the $\lambda$ - line, there are the $L(H)-$ type consumers. There exists an indifferent $\theta-$ type consumer $x_{\theta}$, and consumers on the left of $x_{\theta}$ buy from $R_{1}$, and those on the right of $x_{\theta}$ buy from $R_{2}$.

Therefore, the gross demand for retailers 1 and 2 are, respectively,

$$
\begin{aligned}
& q_{1}=\lambda x_{H}+(1-\lambda) x_{L}, \\
& q_{2}=\lambda\left(1-x_{H}\right)+(1-\lambda)\left(1-x_{L}\right) .
\end{aligned}
$$

The manufacturer's and the two retailers' profit functions are as follows:

$$
\begin{gathered}
\pi_{m}=w\left(q_{1}+q_{2}\right), \\
\pi_{\mathrm{ri}}=\left(p_{i}-w\right) q_{i} .
\end{gathered}
$$

Without loss of generality, we assume that the manufacturer's production cost and the two retailers' unit selling costs are zero, which is also adopted in the literature of $\mathrm{Li}$ et al. [21], Xiao et al. [22], and Kuksov and Liao [23]. The 
TABLE 1: Notations.

\begin{tabular}{|c|c|}
\hline Notation & Description \\
\hline$v$ & The utility a consumer derives from the product \\
\hline$\alpha_{H}\left(\alpha_{L}\right)$ & The price sensitivity of consumers with a high (low) price sensitivity \\
\hline$\lambda \in(0,1)$ & The fraction of consumers with a high price sensitivity \\
\hline$\beta \in(0,1)$ & The consumers' difference with respect to price sensitivity \\
\hline$t$ & The consumers' unit transportation cost \\
\hline$x \in(0,1)$ & The location of each consumer in the linear market \\
\hline$x_{\theta}$ & The location of the $\theta$ - type indifferent consumer when the retailer does not acquire informa \\
\hline$x_{k, H}\left(x_{k, L}\right)$ & $\begin{array}{c}\text { The location of the indifferent consumer with a high (low) price sensitivity in market } k(k=A, B) \text { when the retailer acquires } \\
\text { information }\end{array}$ \\
\hline $\begin{array}{l}\pi_{r i}, \pi_{m}, \pi_{t} \\
\text { Decision vi }\end{array}$ & $\begin{array}{l}\text { The retailer } i \text { 's profit, } i=1,2 \text {, the manufacturer's profit and the whole supply chain's profit } \\
\text { iables }\end{array}$ \\
\hline$w$ & The manufacturer's wholesale price \\
\hline$p_{i}$ & The retailer $i$ 's price when she (he) $d$ \\
\hline$p_{i k, H}\left(p_{i k, L}\right)$ & $\begin{array}{c}\text { The retailer } i \text { 's price for consumers with a high (low) price sensitivity in market } k(k=A, B) \text { when she (he) acquires } \\
\text { information }\end{array}$ \\
\hline$q_{i}$ & The retailer $i$ 's order quantity \\
\hline
\end{tabular}

main managerial insights remain unchanged when this assumption is relaxed.

Following the standard backward induction approach, we characterize the manufacturer's and the two retailers' equilibrium price in Proposition 1.

Proposition 1. In the NN model, the manufacturer' optimal wholesale price and the two retailers' optimal retail prices are

$$
\left\{\begin{array}{l}
w^{\mathrm{NN} *}=\frac{2 v-(3+2(1-\lambda) \beta) t}{2+2(1-\lambda) \beta}, \\
p_{1}^{\mathrm{NN} *}=p_{2}^{\mathrm{NN} *}=\frac{2 v-t}{2+2(1-\lambda) \beta} .
\end{array}\right.
$$

The superscript $\mathrm{NN}^{*}$ denotes the optimal solutions. In the remainder of this paper, we use a similar marking method.

Substituting the manufacturer's and the two retailers' optimal prices into equations (1)-(4), we get the optimal profits of the supply chain members:

$$
\left\{\begin{array}{l}
\pi_{r 1}^{\mathrm{NN} *}=\pi_{r 2}^{\mathrm{NN} *}=\frac{t}{2} \\
\pi_{m}^{\mathrm{NN} *}=\frac{2 v-(3+2(1-\lambda) \beta) t}{2+2(1-\lambda) \beta} .
\end{array}\right.
$$

The total supply chain's profit is

$$
\pi_{t}^{\mathrm{NN} *}=\frac{2 v-t}{2+2(1-\lambda) \beta} .
$$

From Proposition 1, we can see that, in the NN model, two retailers' selling prices are the same because of the symmetry between them. From the Proposition 1, we can get the following Corollary.

Corollary 1. (i) $\partial w^{N N *} / \partial \lambda>0$ and $\partial p_{i}^{N N *} / \partial \lambda>0$; $\partial w^{N N *} / \partial \beta<0$ and $\partial p_{i}^{N N *} / \partial \beta<0, i=1,2$.

Corollary 1 explores, in the scenario where no retailer acquires information and each sets a uniform price, how the

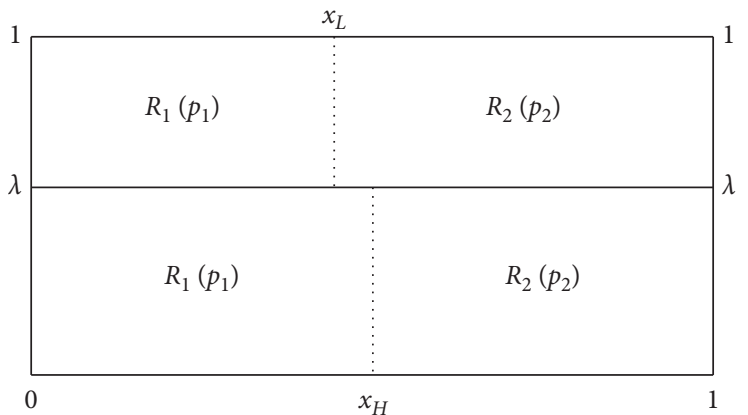

FIGURE 2: Consumers' distribution and retailers' market shares in the NN model.

optimal wholesale price and retail prices are affected by the fraction of $H$ - type consumers and the difference in terms of price sensitivity. Corollary 1(i) shows that the manufacturer's optimal wholesale price and retailers' retail prices increase with the fraction of $H$ - type consumers. The reason is that the price sensitivities of both types $(H-$ type or $L-$ type) decrease with the increase of $\lambda$. As a result, the two retailers can charge a higher price for all consumers and the manufacturer can set a higher wholesale price for two retailers accordingly.

Moreover, Corollary 1(ii) investigates that the wholesale price charged by the manufacturer and the selling prices set by two retailers decrease with the consumers' difference in price sensitivity. A higher $\beta$ means a larger difference in price sensitivity between two types of consumers $\left(\alpha^{H}-\alpha^{L}\right)$, implying that, in the NN model, if the consumers' difference in price sensitivity is large, the two retailers should set low retail prices for consumers and the manufacturer should set a low wholesale price for two retailers.

3.2. IN Model. Now, consider the scenario in which only one retailer acquires information and price discriminates. It can be either $R_{1}$ acquires information and price discriminates (IN) or $R_{2}$ acquires information and price discriminates 
(NI). The two situations are symmetric, so we only consider the former, IN. In the IN model, $R_{1}$ sets $p_{1 k, \theta}$ for $\theta$-type consumers in market $k$, with $\theta=\{L, H\}$ and $k=\{A, B\}$, while $R_{2}$ sets a same price $p_{2}$ for all consumers in both markets. Consider a generic indifferent $\theta$ - type consumer, which can be obtained by $\alpha_{\theta} p_{1 k, \theta}+t x_{k, \theta}=\alpha_{\theta} p_{2}+t\left(1-x_{k, \theta}\right)$. Therefore, the location of $\theta$-type indifferent consumer is

$$
x_{k, \theta}=\frac{\alpha_{\theta}\left(p_{2}-p_{1 k, \theta}\right)+t}{2 t} .
$$

As shown in Figure 3, there exists an indifferent $\theta-$ type consumer $x_{A, \theta}$ in market $A$ and consumers on the left (right) of $x_{A, \theta}$ buy from $R_{1}\left(R_{2}\right)$. Similarly, the indifferent $\theta$-type consumer $x_{B, \theta}$ in market $B$ segments market $B$ into $R_{1}$ 's and $R_{2}$ 's markets (price discrimination allows $R_{1}$ to charge lower prices for consumers with different price sensitivities in market $B$ to steal some consumers from $R_{2}$ (customer poaching effect) and, in the meanwhile, receives a high profit margin in market $A$ at the cost of losing some consumers to $R_{2}$ (intensified competition effect) [24].).

Therefore, the gross demand for retailers 1 and 2 are, respectively,

$$
\begin{aligned}
q_{1}= & \lambda x_{A, H}+(1-\lambda) x_{A, L}+\lambda\left(x_{B, H}-\frac{1}{2}\right) \\
& +(1-\lambda)\left(x_{B, L}-\frac{1}{2}\right), \\
q_{2}= & \lambda\left(\frac{1}{2}-x_{A, H}\right)+(1-\lambda)\left(\frac{1}{2}-x_{A, L}\right)+\lambda\left(1-x_{B, H}\right) \\
& +(1-\lambda)\left(1-x_{B, L}\right) .
\end{aligned}
$$

The profit functions of the manufacturer and the two retailers are

$$
\begin{aligned}
\pi_{m}= & w\left(q_{1}+q_{2}\right) \\
\pi_{r 1}= & p_{1 A, H} \lambda x_{A, H}+p_{1 A, L}(1-\lambda) x_{A, L}+p_{1 B, H} \lambda\left(x_{B, H}-\frac{1}{2}\right) \\
& +p_{1 B, L}(1-\lambda)\left(x_{B, L}-\frac{1}{2}\right)-w q_{1},
\end{aligned}
$$$$
\pi_{r 2}=\left(p_{2}-w\right) q_{2}
$$

The following proposition shows the manufacturer's and the two retailers' equilibrium prices.
Proposition 2. In the IN model, the manufacturer's optimal wholesale price and the two retailers' optimal retail prices are

$$
\left\{\begin{array}{l}
w^{\mathrm{IN}^{*}}=\frac{8 v-9 t-3(1-\lambda) \beta t}{8(1+(1-\lambda) \beta)} \\
p_{1 A, H}^{\mathrm{IN}^{*}}=\frac{8 v-3 t-(1-\lambda) \beta t}{8(1+(1-\lambda) \beta)} \\
p_{1 A, L}^{\mathrm{IN}^{*}}=\frac{\lambda(1-\lambda) t \beta^{2}+((4 t-8 V) \lambda+3 t) \beta+8 v-3 t}{8(1-\lambda \beta)(1+(1-\lambda) \beta)} \\
p_{1 B, H}^{\mathrm{IN}}=p_{1 B, L}^{\mathrm{IN}}=\frac{8 v-7 t-(1-\lambda) t \beta}{8(1+(1-\lambda) \beta)} \\
p_{2}^{\mathrm{IN}}=\frac{8 v-5 t+(1-\lambda) t \beta}{8(1+(1-\lambda) \beta)}
\end{array}\right.
$$

Substituting the manufacturer's and the two retailers' optimal prices into equations (8)-(12), we get the supply chain members' optimal profits:

$$
\left\{\begin{array}{l}
\pi_{r 1}^{\mathrm{IN} *}=\frac{\left(3 \lambda(\lambda-1) \beta^{2}+5(1-2 \lambda) \beta+5\right) t}{16(1-\lambda \beta)(1+(1-\lambda) \beta)} \\
\pi_{r 2}^{\mathrm{IN} *}=\frac{t}{4} \\
\pi_{m}^{\mathrm{IN} *}=\frac{8 v-9 t-3(1-\lambda) \beta t}{8(1+(1-\lambda) \beta)} .
\end{array}\right.
$$

The total supply chain's profit is

$$
\pi_{t}^{\mathrm{IN} *}=\frac{-(1-\lambda) \lambda t \beta^{2}+((6 t-16 v) \lambda+3 t) \beta+16 v-9 t}{16(1-\lambda \beta)(1+(1-\lambda) \beta)}
$$

From Proposition 2, we can get Corollary 2.

Corollary 2. (i) $p_{1 A, \theta}^{I N *}>p_{2}^{I N *}$ and $p_{1 B, \theta}^{I N *}<p_{2}^{I N *}$; $\pi_{r 1}^{I N *}>\pi_{r 2}^{I N *}$.

Corollary 2(i) finds that, in theIN model, $R_{1}$ 's retail price is higher than $R_{2}$ 's retail price in her strong market (market $A$ ) and is lower than $R_{2}$ 's retail price in her weak market (market $B$ ). That means, after acquiring information and price discriminating, $R_{1}$ is aggressive in her weak market and unaggressive in her strong market [25]. Because when $R_{1}$ 


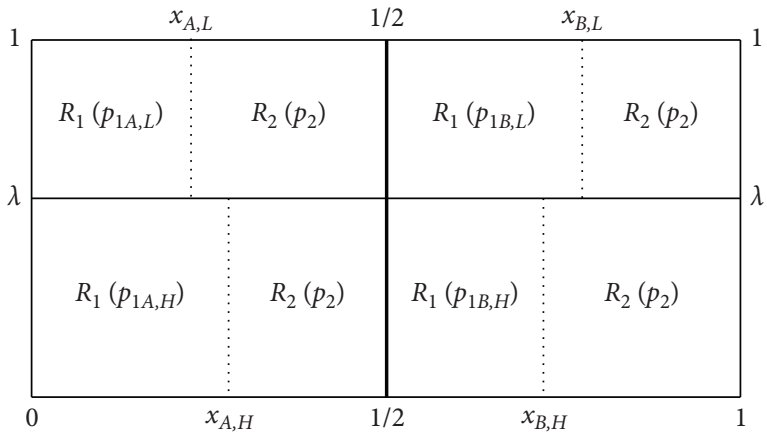

FIGURE 3: Consumers' distribution and retailers' market shares in the IN model.

acquires information and price discriminates, she can distinguish between her own strong market (market $A$ ) and weak market (market $B$ ). In this case, $R_{1}$ tries to steal more her rival's consumers by reducing retail price in market $B$ without lowering price to her own loyal consumers in market $A$.

Moreover, Corollary 2(ii) investigates that $R_{1}$ gets higher profit than $R_{2}$ in the scenario, where only $R_{1}$ acquires information and price discriminates. In other words, the retailer acquiring information and price discriminating is more competitive than the retailer not acquiring information and setting a uniform price, so acquiring information and price discriminating is the preferred and beneficial strategy for the retailer. The reason is that, in the IN model, $R_{1}$ can set a low price in rival's strong market (market $B$ ) to steal her rival's consumers without lowing price to her own loyal consumers. $R_{2}$ responds to this aggressive pricing in his strong market by lowering his price, leading to the reduce of his profit.

3.3. II Model. Now, consider the scenario where both retailers acquire information and set different prices for different-type consumers in market $A$ and $B$ (see Figure 4). In this case, consider a generic indifferent $\theta$ - type consumer, with $\theta=\{L, H\}$, which can be obtained by $\alpha_{\theta} p_{1 k, \theta}+t x_{k, \theta}=\alpha_{\theta} p_{2 k, \theta}+t\left(1-x_{k, \theta}\right)$, where $k=\{A, B\}$. Therefore, the location of $\theta$ - type indifferent consumer is

$$
x_{k, \theta}=\frac{\alpha_{\theta}\left(p_{2 k, \theta}-p_{1 k, \theta}\right)+t}{2 t} .
$$

Therefore, the gross demand for retailers 1 and 2 are, respectively,

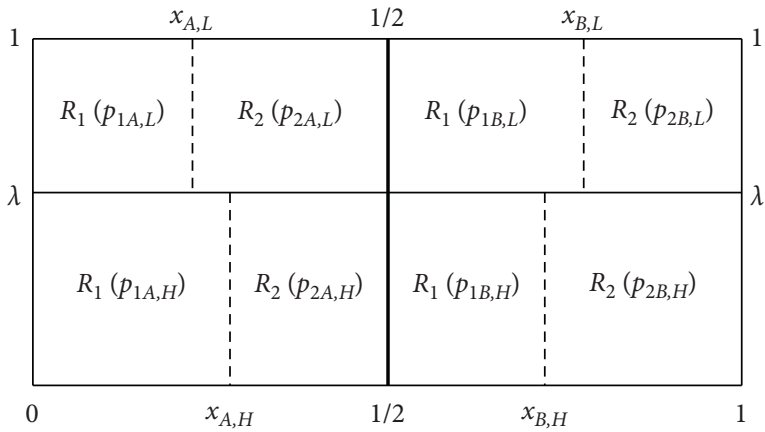

FIGURE 4: Consumers' distribution and retailers' market shares in the II model.

$$
\begin{aligned}
q_{1}= & \lambda x_{A, H}+(1-\lambda) x_{A, L}+\lambda\left(x_{B, H}-\frac{1}{2}\right) \\
& +(1-\lambda)\left(x_{B, L}-\frac{1}{2}\right), \\
q_{2}= & \lambda\left(\frac{1}{2}-x_{A, H}\right)+(1-\lambda)\left(\frac{1}{2}-x_{A, L}\right)+\lambda\left(1-x_{B, H}\right) \\
& +(1-\lambda)\left(1-x_{B, L}\right) .
\end{aligned}
$$

The profit functions of the manufacturer and the two retailers are

$$
\begin{aligned}
\pi_{m}= & w\left(q_{1}+q_{2}\right) \\
\pi_{r 1}= & p_{1 A, H} \lambda x_{A, H}+p_{1 A, L}(1-\lambda) x_{A, L} \\
& +p_{1 B, H} \lambda\left(x_{B, H}-\frac{1}{2}\right) \\
& +p_{1 B, L}(1-\lambda)\left(x_{B, L}-\frac{1}{2}\right)-w q_{1}, \\
\pi_{r 2}= & p_{2 A, H} \lambda\left(\frac{1}{2}-x_{A, H}\right)+p_{2 A, L}(1-\lambda)\left(\frac{1}{2}-x_{A, L}\right) \\
& +p_{2 B, H} \lambda\left(1-x_{B, H}\right)+p_{2 B, L}(1-\lambda)\left(1-x_{B, L}\right)-w q_{2} .
\end{aligned}
$$

The following proposition shows the manufacturer's and the two retailers' equilibrium prices.

Proposition 3. In the scenario of II, the manufacturer's optimal wholesale price and the two retailers' optimal retail prices are 


$$
\left\{\begin{array}{l}
w^{\mathrm{II} *}=\frac{v-t}{1+(1-\lambda) \beta}, \\
p_{1 A, H}^{\mathrm{II} *}=p_{2 B, H}^{\mathrm{II} *}=\frac{3 v-t}{3(1+(1-\lambda) \beta)} \\
p_{1 B, H}^{\mathrm{II} *}=p_{2 A, H}^{\mathrm{II} *}=\frac{3 v-2 t}{3(1+(1-\lambda) \beta)} \\
p_{1 A, L}^{\mathrm{II} *}=p_{2 B, L}^{\mathrm{II} *}=\frac{(3 v-t)(1-\lambda \beta)+2 \beta t}{3(1-\lambda \beta)(1+(1-\lambda) \beta)} \\
p_{1 B, L}^{\mathrm{II} *}=p_{2 A, L}^{\mathrm{II} *}=\frac{(3 v-2 t)(1-\lambda \beta)+\beta t}{3(1-\lambda \beta)(1+(1-\lambda) \beta)} .
\end{array}\right.
$$

Substituting (21) into equations (17)-(20), we get the optimal profits of the supply chain members:

$$
\left\{\begin{array}{l}
\pi_{r 1}^{\mathrm{II} *}=\pi_{r 2}^{\mathrm{II} *}=\frac{5 t(1+(1-2 \lambda) \beta)}{18(1-\lambda \beta)(1+(1-\lambda) \beta)}, \\
\pi_{m}^{\mathrm{II} *}=\frac{v-t}{1+(1-\lambda) \beta} .
\end{array}\right.
$$

The total supply chain's profit is

$$
\pi_{t}^{\mathrm{II} *}=\frac{((-t-9 v) \lambda+5 t) \beta-4 t+9 v}{9(1-\lambda \beta)(1+(1-\lambda) \beta)} .
$$

Proposition 3 shows that when both retailers acquire information and price discriminate, the two retailers will charge the same prices in their strong (weak) market. That means when the two retailers have the same choice of information acquisition and price discrimination, their equilibrium solutions will be identical due to our symmetrical assumptions about the parameters between them. From Proposition 3, we can get Corollary 3.

Corollary 3. (i) $\partial w^{I I *} / \partial \lambda>0$ and $\partial p_{i k, \theta}^{I I *} / \partial \lambda>0$; (ii) $\partial w^{I I *} / \partial \beta<0, \quad \partial p_{i k, H}^{I I *} / \partial \beta<0, \quad$ and $\partial p_{i k, L}^{I I *} / \partial \beta>0, \quad i=1,2$, $k=A, B$, and $\theta=L, H$.

Similar to Corollary 1, Corollary 3(i) shows that the wholesale price set by the manufacturer and the selling prices set by the two retailers increase with the fraction of $H-$ type consumers, $\lambda$. The reason is that the price sensitivities of both types decrease when $\lambda$ increases. Therefore, the two retailers can charge a higher price on both types of consumers, and the manufacturer can charge a higher wholesale price for both retailers accordingly.

Furthermore, Corollary 3(ii) reveals that the wholesale price of the manufacturer decreases with the increase of the consumers' difference in price sensitivity, $\beta$. Moreover, the two retailers' selling prices for $H$ - type consumers decrease with $\beta$ while the two retailers' selling prices for $L$-type consumers always increase with $\beta$. Indeed, the $L$-type consumers' price sensitivity decreases with the increase of $\beta$, while $H$-type consumers' price sensitivity increases with the increase of $\beta$. Therefore, the retailer can set a higher (lower) price on $L$-type $(H$-type) consumers if $\beta$ increase.

3.4. Model Comparisons. In this section, we compare and analyze the supply chain members' profits among three models: (i) no retailer acquires information and each sets a uniform price (NN); (ii) only one retailer acquires information and price discriminates (IN); and (iii) both retailers acquire information and price discriminate (II). It is supposed that the market is full covered under all the above three models, that is, the condition $t<\min \left(t_{1}, t_{2}, t_{3}\right)$ always holds in the following analyses.

Firstly, comparing the two retailers' profits among the three models shows the following.

\section{Corollary 4}

(i) For retailer 1, we have

(a) $\pi_{r 1}^{I I *}>\pi_{r 1}^{N N *}>\pi_{r 1}^{I N *}$, if $\beta \in\left(\beta_{2}, 1\right)$ and $(8 / 9)<\lambda<1$

(b) $\pi_{r 1}^{N N *}>\pi_{r 1}^{I I *}>\pi_{r 1}^{I N *}$, if $\beta \in\left(\beta_{1}, \beta_{2}\right),(8 / 9)<\lambda<1$, and $\beta \in\left(\beta_{1}, 1\right),(10 / 27)<\lambda \leq(8 / 9)$

(c) $\pi_{r 1}^{N N *}>\pi_{r 1}^{I N *}>\pi_{r 1}^{I I *}$, if $\beta \in\left(0, \beta_{1}\right),(10 / 27)<\lambda<1$, and $\beta \in(0,1), \lambda \leq(10 / 27)$

(ii) For retailer 2, we have

(a) $\pi_{r 2}^{I I *}>\pi_{r 2}^{N N *}>\pi_{r 2}^{I N *}$, if $\beta \in\left(\beta_{2}, 1\right),(8 / 9)<\lambda<1$

(b) $\pi_{r 2}^{N N *}>\pi_{r 2}^{I I *}>\pi_{r 2}^{I N *}$, if $\beta \in\left(0, \beta_{2}\right), \quad(8 / 9)<\lambda<1$, and $\beta \in(0,1), 0<\lambda \leq(8 / 9)$, where $\beta_{1}=(5(1-$ $\left.2 \lambda)+\sqrt{25+440 \lambda-440 \lambda^{2}}\right) /(54 \lambda(1-\lambda))$ and $\beta_{2}=\left(4-8 \lambda+\sqrt{-80 \lambda^{2}+80 \lambda+16}\right) / \quad(18 \lambda(1-$ $\lambda)$

Corollary 4 shows the relationships of two retailers' optimal profits among three models. First, we can find from Corollaries 4(i) (a) and 4(ii) (a) that when the consumers' difference in price sensitivity is sufficiently large and there exist lots of $H$-type consumers, i.e., $\beta \in\left(\beta_{2}, 1\right)$, $(8 / 9)<\lambda<1$, the two retailers' profits is the highest in the II model compared to that in NN and IN models. This is intuitive because the price sensitivities of two types ( $L-$ type and $H-$ type) of consumers decrease with the increase of $\lambda$ $\left(\partial \alpha_{L} / \partial \lambda<0\right.$ and $\left.\partial \alpha_{H} / \partial \lambda<0\right)$. As a result, when the fraction of $H$ - type is large, the two retailers can set high retail prices for two types of consumers to gain more profits $\left(\partial p_{i k, \theta}^{\mathrm{II} *} / \partial \lambda>0\right)$. Furthermore, the market competition intensity reduces if consumers' difference in terms of price sensitivity increases, which also allows the two retailers to set high retail prices for consumers in the two markets.

However, as the difference in price sensitivity reduces to a certain level and the fraction of high-price-sensitivity consumers is in a feasible interval, i.e., $\beta<\beta_{2},(8 / 9)<\lambda<1$, or the fraction of consumers with a high price sensitivity reduces to a certain level, i.e., $\beta \in(0,1), 0<\lambda \leq(8 / 9)$, the 
strategy $\mathrm{NN}$ allows the two retailers to gain the highest profits compared with other two models (Corollaries 4(i) (b and c) and 4(ii) (b)). The reason is in the following.

On the one hand, if the difference in price sensitivity is small, both retailers will set high retail prices for consumers in $\mathrm{NN}$ model $\left(\partial p_{i}^{\mathrm{NN} *} / \partial \beta<0\right)$ to obtain more profits correspondingly. Besides, a high fraction of $H-$ type consumers implies a low price sensitivity of type $\theta(\theta=L, H)$, under which the selling prices are also high $\left(\partial p_{i}^{\mathrm{NN} *} / \partial \lambda>0\right)$. Therefore, the two retailers' profits are the highest in the scenario where no retailer acquires information and each sets a uniform price due to the joint effect of the $\beta$ and $\lambda$. On the other hand, if the fraction of $H$ - type consumers is low, no matter whether the difference is high or low, i.e., $\beta \in(0,1), 0<\lambda \leq(8 / 9)$, the two retailers' profits are the highest in the NN model because, under this condition, acquiring information and price discriminating will intensify competition of retailers and reduce their profits.

Moreover, Corollaries 4(i and ii) also show that given $R_{2}$ does not acquire information and sets a same retail price for all consumers, and acquiring information and price discriminating of $R_{1}$ has a negative effect on herself and a negative spillover effect on the $R_{2}\left(\pi_{r 1}^{\mathbb{N} *}<\pi_{r 1}^{\mathrm{NN} *}\right.$ and $\left.\pi_{r 2}^{\mathrm{IN} *}<\pi_{r 2}^{\mathrm{NN} *}\right)$. This is because, if only $R_{1}$ acquires information and price discriminates, she will charge a low retail price in her rival's strong market (market $B$ ) to poach $R_{2}$ 's consumers without lowering price in her strong market (market $A$ ). $R_{2}$ responds to this aggressive pricing in his strong market (market $B$ ) by lowering his price $\left(p_{2}^{\mathrm{IN} *}<p_{2}^{\mathrm{NN} *}\right)$. As a result, compared with the case where no retailer acquires information and each sets a uniform price, the intensified completion in both markets resulting from $R_{1}{ }^{\prime}$ information acquisition and price discrimination leads to overall competition. The results in Corollary 4 can be pictorially shown in Figures 5 and 6.

Next, comparing the manufacturer's profits among three models shows the following.

Corollary 5. $\pi_{m}^{I I *}>\pi_{m}^{I N *}>\pi_{m}^{N N *}$.

Corollary 5 indicates the manufacturer's optimal profits comparison among three models. It is interesting to show that the manufacturer gets the lowest profit in the NN model and gets the highest profit in the II model. In other words, compared to the scenario where no retailer acquires information and each sets a uniform price, one retailer or both retailers acquiring information and price discriminating makes the manufacturer better off $\left(\pi_{m}^{\mathrm{II} *}>\pi_{m}^{\mathrm{NN} *}\right.$ or $\left.\pi_{m}^{\mathrm{IN} *}>\pi_{m}^{\mathrm{NN} *}\right)$. The reason is that when a retailer chooses to acquire information and price discriminate, the manufacturer charges a high wholesale price for both retailers $\left(w^{\mathrm{II} *}>w^{\mathrm{IN} *}>w^{\mathrm{NN} *}\right)$. As a result, acquiring information and price discriminating of retailers always has a positive effect on the manufacturer. A numerical example shows these results in Figure 7.

From Figure 7, we can find that the manufacturer gets the highest profit in the II model and gets the lowest profit in the NN model, regardless of the changes of $\beta$ and $\lambda$. Moreover, we also can find the effects of the fraction of $H-$ type consumers and the consumers' difference in price sensitivity on the manufacturer's profits. Specifically, the

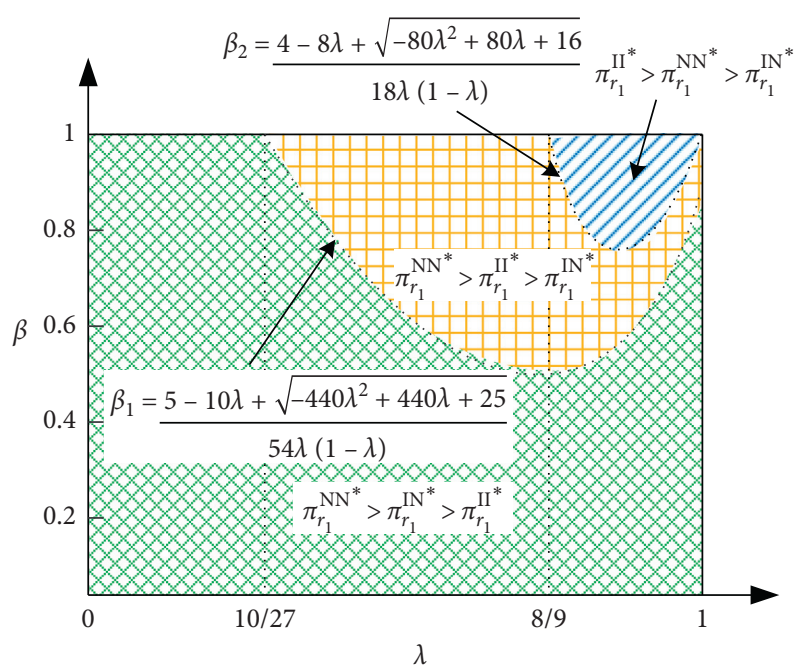

FIGURE 5: Comparison of $R_{1}$ 's profits among three models.

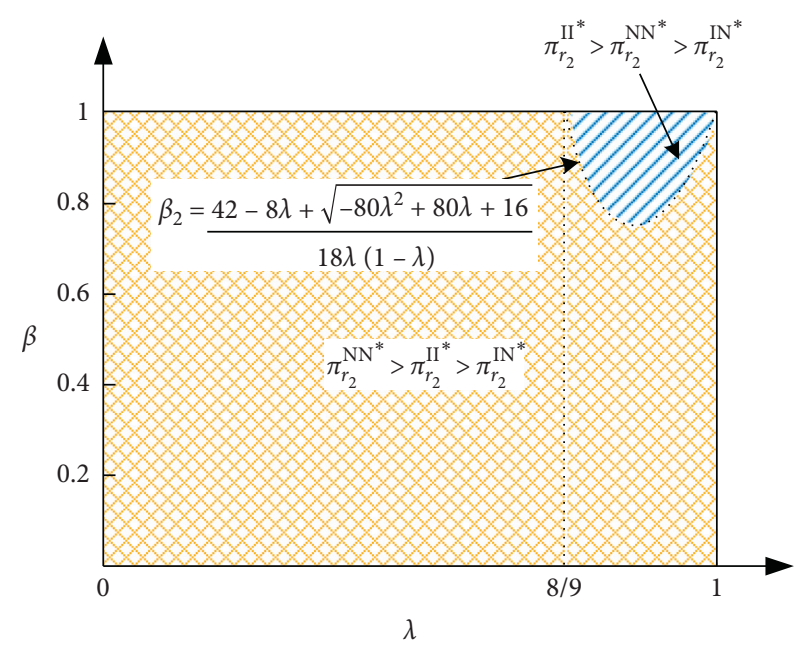

FiguRE 6: Comparison of $R_{2}$ 's profits among three models.

manufacturer's profit decreases with the increase of $\beta$ and increases with the increase of $\lambda$. The reason is that the wholesale price of the manufacturer for both retailers decrease (increase) with the increase of $\beta(\lambda)$, i.e., $(\partial w / \partial \lambda)^{j *}>0$ and $(\partial w / \partial \beta)^{j *}<0, j=\mathrm{NN}, \mathrm{IN}$, II.

Finally, comparing the whole supply chain's profits among three models shows the following.

Corollary 6. (i) $\pi_{t}^{I I *}>\pi_{t}^{N N *}>\pi_{t}^{I N *}$, if $\beta \in\left(0, \beta_{3}\right)$; (ii) $\pi_{t}^{I I *}>\pi_{t}^{I N *}>\pi_{t}^{N N *}$, if $\quad \beta \in\left(\beta_{3}, 1\right)$, where $\beta_{3}=\left(3-2 \lambda-\sqrt{8 \lambda^{2}-16 \lambda+9}\right) / 2 \lambda(1-\lambda)$.

Corollary 6 shows the whole supply chain's profits comparison among three models. We can find that, in the case where both retailers acquire information and price discriminate, the whole supply chain can gain the highest profit than the other two cases, regardless of the change of the consumers' difference in terms of price sensitivity. The potential reason is that when both retailers acquire 


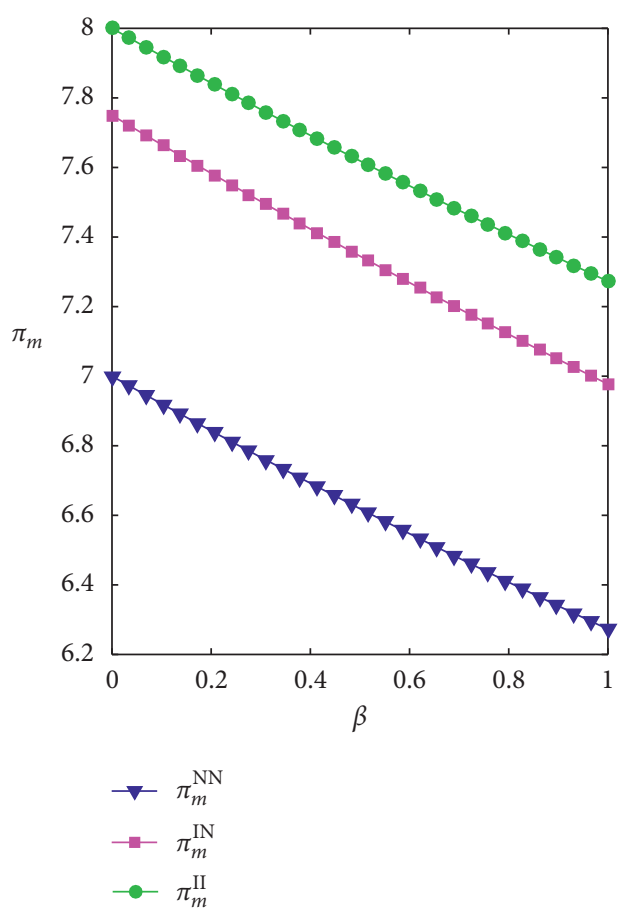

(a)

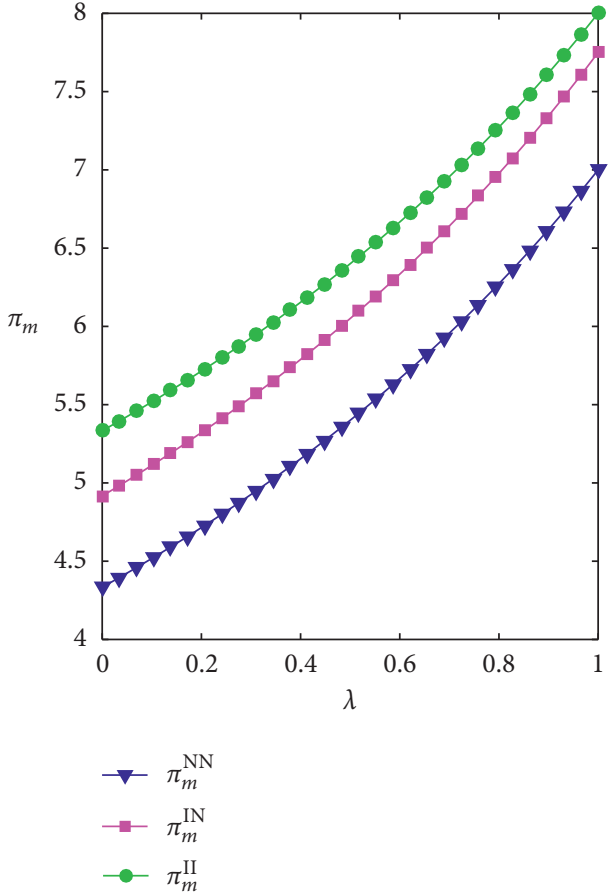

(b)

Figure 7: Comparisons on the manufacturer's profit among three models. (a) The manufacturer's profits with respect to $\beta$. (b) The manufacturer's profits with respect to $\lambda$. Note: (a) $v=10, t=2$, and $\lambda=0.9$; (b) $v=10, t=2$, and $\beta=0.5$.

information and price discriminate, the manufacturer can get the highest profit compared to NN and IN models $\left(\pi_{m}^{\mathrm{II} *}>\pi_{m}^{\mathrm{IN} *}>\pi_{m}^{\mathrm{NN} *}\right)$, and, meanwhile, the increased profit of the manufacturer can compensate for the decreased profits of the two retailers. Therefore, compared to the other two cases, the profit of the whole supply chain is the highest in the scenario where both retailers obtain information and set different prices for different-type consumers.

In addition, we can observe from Corollary 6(i) that the whole supply chain may get a lower profit in the IN model than that in the NN model if the value of consumers' difference with respect to price sensitivity is small $\left(\pi_{t}^{\mathrm{IN} *}<\pi_{t}^{\mathrm{NN} *}\right)$. Otherwise, the whole supply chain's profit in the NN model is lower than that in the IN model (Corollary 6(ii)). This is because if the consumers' difference in price sensitivity is less than $\beta_{3}$, the decrease of both retailers' profits is only partially compensated by the increase of the manufacturer's profit in the IN model compared with the NN model. The results in Corollary 6 are pictorially shown in Figure 8.

Now, we explore the two retailers' decisions of information acquisition and price discrimination. Retailers 1 and 2 simultaneously and independently choose to acquire information and price discrimination (denoted by $I$ ) or not (denoted by $N$ ). Therefore, the retailer's strategy space is given by $\{I, N\}$. The two retailers' profits of the four models (NN, NI, IN, and II) are summarized in Table 2. By comparing the two retailers' profits among the four scenarios, we can summarize the two retailers' equilibrium information acquisition and price discrimination decisions, as shown in Proposition 4.

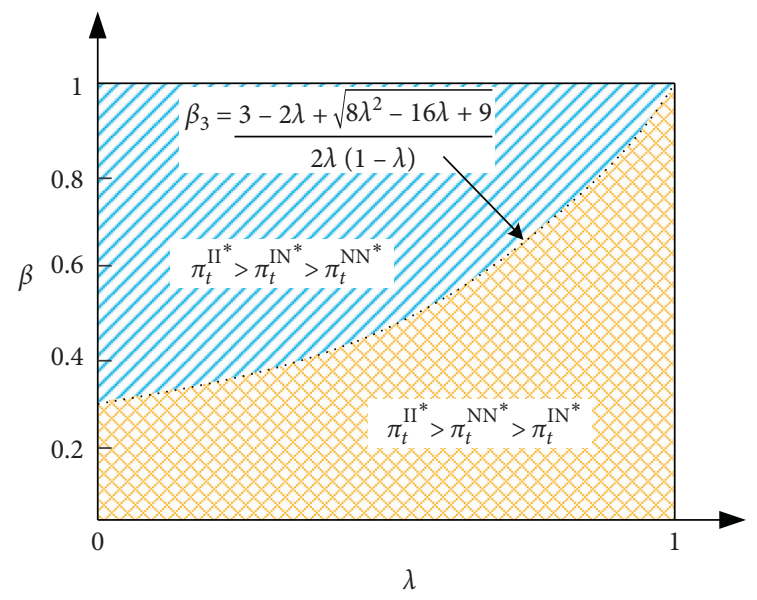

FIGURE 8: The whole supply chain's profits comparison among three models.

Proposition 4. The two retailers' equilibrium strategies of information acquisition and price discrimination are as follows:

(i) When $\lambda \in[(8 / 9), 1)$, the equilibrium information acquisition and price discrimination decisions for two retailers are given by one of two possible structures:

(a) If $\beta \geq \beta_{2}$, the unique equilibrium is $(I, I)$

(b) Otherwise, the unique equilibrium is $(N, N)$.=

(ii) When $\lambda \in(0,(8 / 9))$, the unique equilibrium is $(N, N)$. 


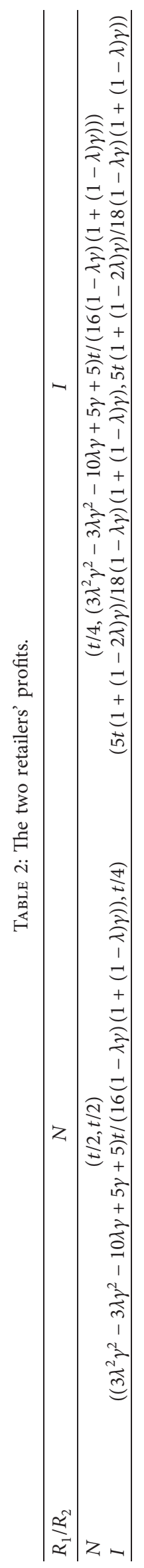


Proposition 4 characterizes the two retailers' equilibrium strategies of information acquisition and price discrimination depend on the fraction of $H$ - type consumers and the consumers' difference in price sensitivity. Proposition 4(i) shows that when the fraction of $H$ - type consumers is large, i.e., $\lambda \in[(8 / 9), 1)$, the two retailers may have two choices of information acquisition and price discrimination decisions $-(I, I)$ or $(\mathrm{NN})$. Specifically, if the consumers' difference in price sensitivity is relatively large, i.e., $\beta \geq \beta_{2}$, acquiring information and price discriminating is the dominant strategy for both retailers; otherwise, no retailer acquiring information and each setting a uniform price is the dominant strategy. This is because when $\beta$ increases to a certain level, i.e., $\beta \geq \beta_{2}$, the increase of the equilibrium price on $L-$ type consumers can compensate the decrease of the equilibrium price on $H$-type consumers. Indeed, the price sensitivity of $L$-type consumers decreases with the increase of $\beta$, implying that the two retailers can charge a higher retail prices for $L$ - type consumers after acquiring information and price discriminating. This explains why higher consumers' difference in price sensitivity motivates the two retailers to acquire information and price discriminate to gain more profits.

Moreover, Proposition 4(ii) indicates that when the fraction of $H$-type consumers is relatively small, i.e., $\lambda \in(0,(8 / 9))$, regardless of the change of consumers' difference in price sensitivity, no information acquiring and each setting a uniform price for both retailers are the dominant strategy. This is because that the price sensitivity of $\theta$-type consumers increases with the decrease of $\lambda$, $\theta=\{L, H\}$. As a result, after acquiring information and price discriminating, the two retailers will set low retail prices for both type of consumers, leading to the decrease of their profits. The results in Proposition 4 are pictorially shown in Figure 9.

From Proposition 4, we can find that there are two possible equilibrium information acquisitions and price discrimination strategies for the two retailers, i.e., both retailers acquire information and price discrimination or no retailer acquires information and each sets a uniform price. However, from Corollaries 5 and 6, we can find that when the both retailers choose to acquire information and price discrimination, the manufacturer and the whole supply chain can be better off compared to no retailer acquiring information and each sets a uniform price. Therefore, in Section 4, an incentive contract will be proposed by the manufacturer to motive the two retailers to acquire information and price discriminate and make the manufacturers and the two retailers better than ever.

\section{The Manufacturer's Incentive Contract: A Fixed Fee Contract}

In this section, we design a fixed fee contract [26-29] for the manufacturer to motivate the two retailers to acquire information and price discriminate.

Note that when $\lambda \in[(8 / 9), 1)$ and $\beta \geq \beta_{2}$, the two retailers are willing to acquire information and price discriminate (as

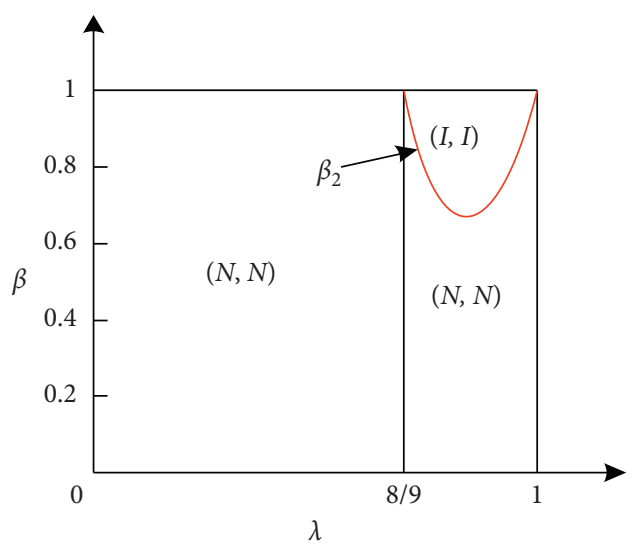

FIgURE 9: The two retailers' optimal strategies about information acquisition and price discrimination.

shown in Proposition 4), implying that, under this condition, the manufacturer does not need to provide a fixed fee contract for two retailers. Therefore, we assume that the conditions $\lambda \in[(8 / 9), 1), \beta \in\left(0, \beta_{2}\right)$, and $\lambda \in(0,(8 / 9))$, $\beta \in(0,1)$, always hold under the scenario where the manufacturer provides a fixed fee contract for two retailers.

We use FC to represent this special case. In the FC model, the manufacturer will give a fixed fee $F$ for the two retailers, respectively, if the two retailers choose to acquire information and price discriminate. The two retailers will adopt the strategy II only if their profits in the II model are higher than those in the NN model. Consequently, the fixed fee contract cannot achieve the motivation unless the fixed fee $F$ is within reasonable ranges.

Proposition 5 characterizes the range of $F$, which ensures that the manufacturer has motivation to provide fixed fee contract and the two retailers are willing to accept this contract.

Proposition 5. If and only if $\underline{F} \leq F \leq \bar{F}$, the manufacturer is willing to provide the fixed fee contract, and, meanwhile, the fixed fee contract can effectively motivate the two retailers to acquire consumers' information and price discriminate, where $\underline{F}=\left(9 \lambda(\lambda-1) \beta^{2}+4(1-2 \lambda) \beta+4\right) t /(18(1-\lambda \beta)(1+$ $(1-\lambda) \beta)$ and $\bar{F}=(1+2(1-\lambda) \beta) t / 4(1+(1-\lambda) \beta)$.

Proposition 5 shows the feasible interval of $F$ ensuring that the two retailers are stimulated successfully to acquire information and price discriminate. Given the range of $F$ in Proposition 5, the manufacturer and the two retailers can gain higher profits in the II model than in the NN model.

According to Proposition 5, we obtain a reasonable interval for the fixed fee $F$ and show it in Figure 10. Here, we assume $t=2$.

We can find from Figure 10 that $\bar{F}>\underline{F}$, which ensures the interval of $F$ is not empty. Moreover, we observe that when $\beta$ and $\lambda$ are large, the value of $\underline{F}$ declines quickly, implying that when the consumers' difference in price sensitivity is sufficiently large and there exists lots of $\mathrm{H}-$ type consumers, and the manufacturer can motivate two 


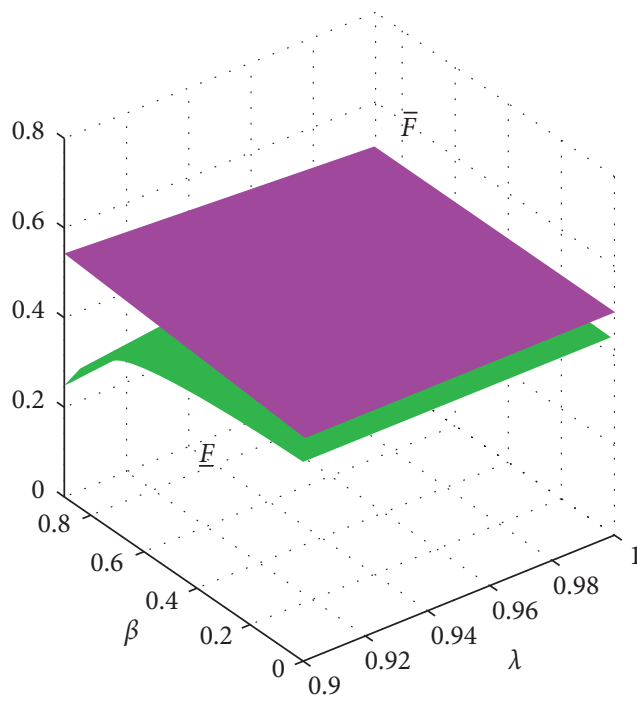

(a)

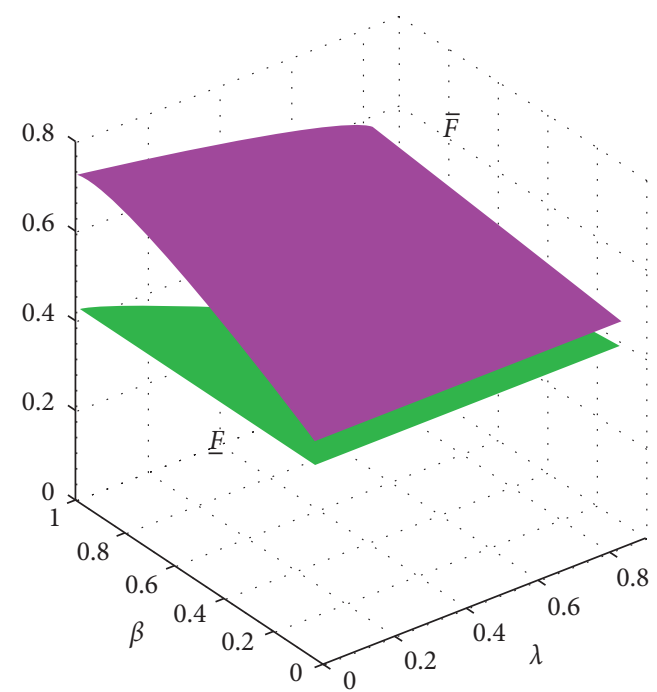

(b)

Figure 10: The change of $F$ by $\lambda$ and $\beta$. (a) $\lambda \in((8 / 9), 1), \beta \in\left(0, \beta_{2}\right)$; (b) $\lambda \in(0,(8 / 9)), \beta \in(0,1)$.

retailers to acquire information and price discriminate by giving them a low fixed fee. On the contrary, the manufacturer needs to give a high fixed fee to motivate the two retailers to adopt strategy II.

\section{Conclusions}

This paper examines the problems of two retailers' information acquisition and price discrimination in the supply chain consisting of a manufacturer and duopoly retailers. We assume that the consumers' purchase history information exogenously and the two retailers endogenously decide whether to acquire information to segment consumers and price them differently. We try to investigate the effect of consumers' difference in price sensitivity on the two retailers' and the manufacturer's pricing decisions. We also explore how the fraction of high pricesensitivity consumers influences the pricing decisions of the manufacturer and the two retailers. Moreover, we study how the strategies of two retailers' information acquisition and price discrimination affect their profits, the manufacturer's performance, and the whole supply chain's performance. Finally, we design an incentive contract to explore whether a win-win situation can be achieved for both the manufacturer and two retailers. We summarize the main findings as follows.

Firstly, we show that the wholesale price of the manufacturer increases with the fraction of high price-sensitivity consumers and decreases with the consumers' difference in terms of price sensitivity. Moreover, we find that if a retailer chooses not to acquire consumers' information and sets the same selling price for all consumers, the retailer's selling price also increases with the fraction of high price-sensitivity consumers and decreases with the consumers' difference in terms of price sensitivity. If a retailer chooses to acquire information and price discriminate for different-type consumers, the retail prices for two types of consumers increase with the fraction of high pricesensitivity consumers. However, the retail price for high (low) price-sensitivity consumers decreases (increases) with the consumers' difference in terms of price sensitivity.

Secondly, we find that the fraction of high price-sensitivity consumers and the consumers' difference in price sensitivity play significant roles in the two retailers' choices of information acquisition and price discrimination. Specifically, when the consumers' difference in price sensitivity is sufficiently large and there exist lots of high price-sensitivity consumers, acquiring information and price discriminating makes the two retailers better off. Otherwise, the two retailers will choose not to acquire information and charge a uniform price for all consumers. Therefore, there exist two possible equilibrium information acquisition decisions for retailers: both retailers acquire information and price discriminate and no retailer acquires information and each sets a uniform price for all consumers. Strategy dominates depend on the fraction of high price-sensitivity consumers and the consumers' difference in price sensitivity.

Thirdly, for the manufacturer and the whole supply chain, the strategy of two retailers acquiring information and price discriminating dominates the strategy of no retailer acquiring information and uniform pricing.

Finally, the common manufacturer can stimulate the two retailers to acquire information and price discriminate by designing a fixed fee contract. When the fixed fee in a reasonable interval, the manufacturer and the two retailers all can gain more profits in the scenario where two retailers acquire information and price discriminate compared to the scenario where no retailer acquires information and each sets a uniform price for all consumers.

There are several directions for future work. In this paper, we have assumed that if retailers choose to acquire information, they can distinguish not only between new and past consumers but also between high and low price-sensitivity consumers. With the improvement of information' quality, future research can explore more consumers' characteristics, such as the preference of service and quality. 
Moreover, this paper assumed that the two competing retailers are symmetric in the supply chain. In reality, retailers differ in cost, information, fairness, and so on. Further work can examine the problem of information acquisition and price discrimination in channel setting where duopoly retailers are asymmetrical.

\section{Appendix}

Proof of Proposition 1. Using backward induction procedure, we first solve the retailers' equilibrium pricing decisions. From the two retailers' profits function, we have

$$
\frac{\partial \pi_{r i}}{\partial p_{i}}=\frac{(1-\lambda)\left(w-2 p_{i}+p_{j}\right) \alpha_{L}+\alpha_{H}\left(w-2 p_{i}+p_{j}\right) \lambda+t}{2 t}
$$

It is easy to calculate that $\partial^{2} \pi_{r i} / \partial p_{i}^{2}=\left((\lambda-1) \alpha_{L}-\alpha_{H} \lambda\right) / t<0$. Therefore, the retailer's profit function is concave in the retail price, $p_{i}$. Then, from $\partial \pi_{r i} / \partial p_{i}=0$, we have $p_{1}=p_{2}=\left(t /\left(\lambda \alpha^{H}+(1-\lambda) \alpha^{L}\right)\right)+w$.

Next, we derive the manufacturer's optimal decision. Substituting the value of $p_{i}$ into the manufacturer's profit function, we get $\partial \pi_{m} / \partial w=1>0$, implying the manufacturer's profit increases with its wholesale price $(w)$. From $t \leq t_{1}$, where $t_{1}$ is given in condition $\alpha_{\theta}\left(p_{1}+p_{2}\right)<2 v-t_{1}$, we have $w \leq(2 v-(3+2(1-\lambda) \beta) t) /(2+2(1-\lambda) \beta)$. Thus, we have $w^{\mathrm{NN}^{*}}=(2 v-(3+2(1-\lambda) \beta) t) /(2+2(1-\lambda) \beta)$.

Substituting the $w^{\mathrm{NN} *}$ into the $p_{1}=p_{2}=\left(t /\left(\lambda \alpha^{H}+(1-\lambda) \alpha^{L}\right)\right)+w, \quad$ we have $p_{1}^{\mathrm{NN}^{*}}=p_{2}^{\mathrm{NN}^{*}}=(2 v-t) /(2+2(1-\lambda) \beta)$.

Proof of Propositions 2 and 3. The proofs are omitted as they are similar with that in Proposition 1.

Proof of Proposition 4. From Table 1, we can derive that

$$
\pi_{r i}^{\mathrm{II}^{*}}-\pi_{r i}^{\mathrm{NN}^{*}}=\frac{\left(9 \lambda(1-\lambda) \beta^{2}+4(2 \lambda-1) \beta-4\right) t}{18(1-\lambda \beta)(1+(1-\lambda) \beta)} .
$$

Thus, we obtain that $\pi_{r i}^{\mathrm{II}} \leq(\geq) \pi_{r i}^{\mathrm{NN}^{*}}$ if $\beta \leq(\geq) \beta_{2} \equiv\left(4-8 \lambda+\sqrt{-80 \lambda^{2}+80 \lambda+16}\right) /(18 \lambda(1-\lambda))$. We can find that $\beta_{2}$ is always positive, but it is lower than 1 only if $\lambda \in[8 / 9,1)$.

Proof of Proposition 5. In the fixed fee contract, in order to stimulate the two retailers to acquire information, the manufacturer gives the two retailers a fixed fee $F$, respectively. In this scenario, the two retailers' profits are

$$
\pi_{r i}^{\mathrm{IC}^{*}}=\frac{5 t(1+(1-2 \lambda) \beta)}{18(1-\lambda \beta)(1+(1-\lambda) \beta)}+F .
$$

The manufacturer's profit is $\pi_{m}^{\mathrm{IC}^{*}}=((\nu-t) /(1+(1-\lambda) \beta))-2 F$, where the superscript IC denotes the scenario where the manufacturer designs an incentive contract to stimulate the two retailers to acquire information.
Thus, by $\pi_{m}^{\mathrm{IC}^{*}} \geq \pi_{m}^{\mathrm{NN}^{*}}$, we can get $F \leq(1+2(1-\lambda) \beta) t / 4(1+(1-\lambda) \beta)$; by $\pi_{r i}^{\mathrm{IC}^{*}} \geq \pi_{r i}^{\mathrm{NN}^{*}}$, we can get $\quad F \geq\left(9 \lambda(\lambda-1) \beta^{2}+4(1-2 \lambda) \beta+4\right) t /(18(1-\lambda \beta)$ $(1+(1-\lambda) \beta))$.

Proof of Corollary 1. From the manufacturer's optimal wholesale price and the two retailers' optimal retail prices shown in Proposition 1, we can derive that

$$
\begin{gathered}
\frac{\partial w^{\mathrm{NN}^{*}}}{\partial \lambda}=\frac{(2 v-t) \beta}{2(1+(1-\lambda) \beta)^{2}}>0, \\
\frac{\partial w^{\mathrm{NN}^{*}}}{\partial \beta}=-\frac{(2 v-t)(1-\lambda)}{2(1+(1-\lambda) \beta)^{2}}<0, \\
\frac{\partial p_{1}^{\mathrm{NN}^{*}}}{\partial \lambda}=\frac{\partial p_{2}^{\mathrm{NN}}}{\partial \lambda}=\frac{2(2 v-t) \beta}{(2+2(1-\lambda) \beta)^{2}}>0, \\
\frac{\partial p_{1}^{\mathrm{NN}}}{\partial \beta}=\frac{\partial p_{2}^{\mathrm{NN}}}{\partial \beta}=-\frac{2(2 v-t)(1-\lambda)}{(2+2(1-\lambda) \beta)^{2}}<0 .
\end{gathered}
$$

Proof of Corollary 2. From the two retailers' optimal price shown in Proposition 2, we can derive that

$$
\begin{aligned}
& p_{1 A, H}^{\mathrm{IN} *}-p_{2}^{\mathrm{IN} *}=\frac{(1-(1-\lambda) \beta) t}{4+4(1-\lambda) \beta}>0, \\
& p_{1 A, L}^{\mathrm{IN} *}-p_{2}^{\mathrm{IN} *}=\frac{(1+\lambda \beta) t}{4(1-\lambda \beta)}>0, \\
& p_{2}^{\mathrm{IN}}-p_{1 B, H}^{\mathrm{IN}^{*}}\left(p_{1 B, L}^{\mathrm{IN}^{*}}\right)=\frac{t}{4}>0, \\
& \pi_{r_{1}}^{\mathrm{IN}}-\pi_{r_{2}}^{\mathrm{IN}^{*}}=\frac{\lambda(1-\lambda) \beta^{2}+(1-2 \lambda) \beta+1}{16(1-\lambda \beta)(1+(1-\lambda) \beta)}>0 .
\end{aligned}
$$

Proof of Corollary 3. We omit the proof of Corollary 3 as it is similar with that in Corollary 1.

Proof of Corollary 4. From the optimal profits of the two retailers in Propositions 1-3, we can derive that

$$
\begin{aligned}
& \pi_{r_{1}}^{\mathrm{IN}}-\pi_{r_{1}}^{\mathrm{NN}^{*}}=\frac{\left(5 \lambda(1-\lambda) \beta^{2}+(6 \lambda-3) \beta-3\right) t}{16(1-\lambda \beta)(1+(1-\lambda) \beta)}<0, \\
& \pi_{r_{2}}^{\mathrm{IN}^{*}}-\pi_{r_{2}}^{\mathrm{NN}^{*}}=-\frac{t}{4}<0, \\
& \pi_{r_{1}}^{\mathrm{II}}-\pi_{r_{1}^{*}}^{\mathrm{IN}}=\frac{\left(27 \lambda(1-\lambda) \beta^{2}+(10 \lambda-5) \beta-5\right) t}{144(1-\lambda \beta)(1+(1-\lambda) \beta)}, \\
& \pi_{r_{1}}^{\mathrm{II}} \geq(\leq) \pi_{r_{1}^{*}}^{\mathrm{IN}^{*}}
\end{aligned}
$$


if $\quad \beta \geq(\leq) \beta_{1} \equiv(5(1-2 \lambda)+\sqrt{25+440 \lambda-440}$

$\left.\lambda^{2}\right) /(54 \lambda(1-\lambda))$. We can find that $\beta_{1}$ is always positive, but it is lower than 1 only if $\lambda \leq 10 / 27$ :

$$
\begin{aligned}
\pi_{r_{2}}^{\mathrm{II}}-\pi_{r_{2}}^{\mathrm{IN}^{*}} & =\frac{9 \lambda(1-\lambda) \beta^{2}+(1-2 \lambda) \beta+1}{36(1-\lambda \beta)(1+(1-\lambda) \beta)}>0 \\
\pi_{r i}^{\mathrm{II}}-\pi_{r i}^{\mathrm{NN}^{*}} & =\frac{\left(9 \lambda(1-\lambda) \beta^{2}+4(2 \lambda-1) \beta-4\right) t}{18(1-\lambda \beta)(1+(1-\lambda) \beta)}, \\
\pi_{r i}^{\mathrm{II}} & \leq(\geq) \pi_{r i}^{\mathrm{NN}^{*}}
\end{aligned}
$$

if $\beta \leq(\geq) \beta_{2} \equiv\left(4-8 \lambda+\sqrt{-80 \lambda^{2}+80 \lambda+16}\right) / 18 \lambda(1-\lambda)$. We can find that $\beta_{2}$ is always positive, but it is lower than 1 only if $\lambda \leq(8 / 9)$.

Proof of Corollaries 5 and 6. The proofs are similar to that of Corollary 4, so we omit it.

\section{Data Availability}

No data were used to support this study.

\section{Conflicts of Interest}

The authors declare no conflicts of interest.

\section{Acknowledgments}

This research was funded by the Social Science Planning Foundation of Qingdao (QDSKL2001005).

\section{References}

[1] B. Caillaud and R. De Nijs, "Strategic loyalty reward in dynamic price discrimination," Marketing Science, vol. 33, no. 5, pp. 725-742, 2014.

[2] Y. Jeong and M. Maruyama, "Commitment to a strategy of uniform pricing in a two-period duopoly with switching costs," Journal of Economics, vol. 98, no. 1, pp. 45-66, 2009.

[3] C. Choe, S. King, and N. Matsushima, "Pricing with cookies: behavior-based price discrimination and spatial competition," Management Science, vol. 64, no. 12, pp. 5669-5687, 2018.

[4] R.-B. Esteves and C. Reggiani, "Elasticity of demand and behaviour-based price discrimination," International Journal of Industrial Organization, vol. 32, pp. 46-56, 2014.

[5] R.-B. Esteves, "Behavior-based price discrimination with retention offers," Information Economics and Policy, vol. 27, pp. 39-51, 2014.

[6] J. Shin and K. Sudhir, "A customer management dilemma: when is it profitable to reward one's own customers?" Marketing Science, vol. 29, no. 4, pp. 671-689, 2010.

[7] B. Jing, "Customer recognition in experience vs. inspection good markets," Management Science, vol. 62, no. 1, pp. 216224, 2016.

[8] A. Pazgal and D. Soberman, "Behavior-based discrimination: is it a winning play, and if so, when?" Marketing Science, vol. 27, no. 6, pp. 977-994, 2008.

[9] K. J. Li and S. Jain, "Behavior-based pricing: an analysis of the impact of peer-induced fairness," Management Science, vol. 62, no. 9, pp. 2705-2721, 2016.
[10] B. Jing, "Behavior-based pricing, production efficiency, and quality differentiation," Management Science, vol. 63, no. 7, pp. 2365-2376, 2017.

[11] K.-E. Rhee and R. Thomadsen, "Behavior-based pricing in vertically differentiated industries," Management Science, vol. 63, no. 8, pp. 2729-2740, 2017.

[12] K. J. Li, "Behavior-based pricing in marketing channels," Marketing Science, vol. 37, no. 2, pp. 310-326, 2018.

[13] J. Zhou, R. Zhao, and B. Wang, "Behavior-based price discrimination in a dual-channel supply chain with retailer's information disclosure," Electronic Commerce Research and Applications, vol. 39, Article ID 100916, 2020.

[14] Q. Liu, T. Otter, and G. M. Allenby, Handbook of Pricing Research in Marketing, Edward Elgar Publishing, Cheltenham, UK, 2009.

[15] M. Löffler, "Measuring willingness to pay: do direct methods work for premium durables?” Marketing Letters, vol. 26, no. 4, pp. 535-548, 2015.

[16] K. M. Miller, R. Hofstetter, H. Krohmer, and Z. J. Zhang, "How should consumers' willingness to pay be measured? an empirical comparison of state-of-the-art approaches," Journal of Marketing Research, vol. 48, no. 1, pp. 172-184, 2011.

[17] Y. Liu, J. Li, W. Ren, and J. Y.-L. Forrest, "Differentiated products pricing with consumer network acceptance in a dual-channel supply chain," Electronic Commerce Research and Applications, vol. 39, p. 100915, 2020.

[18] T. Erdem, J. Swait, and J. Louviere, "The impact of brand credibility on consumer price sensitivity," International Journal of Research in Marketing, vol. 19, no. 1, pp. 1-19, 2002.

[19] S. Colombo, "Behavior- and characteristic-based price discrimination," Journal of Economics \& Management Strategy, vol. 27, no. 2, pp. 237-250, 2018.

[20] J. Tirole, The Theory of Industrial Organization, MIT Press, Cambridge, MA, USA, 1988.

[21] G. Li, L. Li, and J. Sun, "Pricing and service effort strategy in a dual-channel supply chain with showrooming effect," Transportation Research Part E: Logistics and Transportation Review, vol. 126, pp. 32-48, 2019.

[22] L. Xiao, M. Xu, J.-J. Zheng, and S. Huang, "Inducing manufacturer's quality enhancement via retailer's acquisition strategy," Omega, vol. 93, pp. 102032-102041, 2020.

[23] D. Kuksov and C. Liao, "When showrooming increases retailer profit," Journal of Marketing Research, vol. 55, no. 4, pp. 459-473, 2018.

[24] K. S. Corts, "Third-degree price discrimination in oligopoly: all-out competition and strategic commitment," The RAND Journal of Economics, vol. 29, no. 2, pp. 306-323, 1998.

[25] J. Robinson, The Economics of Imperfect Competition, Macmillan, London, UK, 1933.

[26] X. Hong, K. Govindan, L. Xu, and P. Du, "Quantity and collection decisions in a closed-loop supply chain with technology licensing," European Journal of Operational Research, vol. 256, no. 3, pp. 820-829, 2017.

[27] B.-K. Jeong, M. Khouja, and K. Zhao, "The impacts of piracy and supply chain contracts on digital music channel performance," Decision Support Systems, vol. 52, no. 3, pp. 590-603, 2012.

[28] H. Gurnani and M. Erkoc, "Supply contracts in manufacturerretailer interactions with manufacturer-quality and retailer effort-induced demand," Naval Research Logistics, vol. 55, no. 3, pp. 200-217, 2008.

[29] J. Zhang, Q. Cao, and X. He, "Contract and product quality in platform selling," European Journal of Operational Research, vol. 272, no. 3, pp. 928-944, 2019. 